\title{
A IMPORTÂNCIA DO PROJETO POLÍTICO PEGAGÓGICO NA CONSTRUÇÃO DO PROCESSO DE ENSINO-APRENDIZAGEM CONTEXTUALIZADO: um estudo de caso da CEFFA Manoel Monteiro
}

\author{
Matheus Casimiro Soares Ferreira ${ }^{1}$ \\ Meubles Borges Júnior²
}

\begin{abstract}
RESUMO
O texto, analisa criticamente o Projeto Político Pedagógico - PPP da escola Centro Familiar de Formação por Alternância Manoel Monteiro - CEFFA M. M., localizada na comunidade Pau Santo, município de Lago do Junco, estado do Maranhão. Esta escola funciona baseada na pedagogia da alternância, dividindo seu processo formativo entre tempos e espaços distintos, que se efetuam entre a instituição escolar e o meio socioprofissional dos jovens. Assim, a análise é realizada buscando compreender como o processo de contextualização do ensino é concretizado nos processos de ensino-aprendizagem, tomando como base a orientação que dispõem no próprio PPP da escola. Nesse sentido, o trabalho tem como objetivo identificar como o projeto político pedagógico da CEFFA Manoel Monteiro articula os instrumentos pedagógicos da alternância para a efetivação da construção do processo de ensino-aprendizagem contextualizado. Para essa tarefa, construiu-se breves históricos sobre a fundação da escola e o método pedagógico da alternância, para situar o leitor no contexto geográfico, histórico e social do trabalho e na contribuição gerada pela pedagogia da alternância, ao processo de contextualização do ensino na escola. Também, analisou-se o processo de formação, tomando como base as três categorias do processo de contextualização do ensino de ciências. Assim, o trabalho está organizado em introdução, metodologia, resultados e discussões, considerações finais e referências bibliográficas.
\end{abstract}

Palavras-chave: Pedagogia da Alternância. Gestão Democrática. Contextualização do Ensino.

\footnotetext{
1 Graduando da Universidade Federal do Maranhão do Curso de Licenciatura em Educação do Campo; Bacabal-MA, Brasil. Orcid iD: http://orcid.org/0000-0002-2648-3448. Email: matheuscasimiro5@gmail.com

2 Doutor em Agronomia (Solos e Nutrição de Plantas) pela Universidade Federal de Viçosa; Professor da Universidade Federal do Maranhão do Curso de Licenciatura em Educação do Campo, Bacabal-MA, Brasil. Orcid iD: http://orcid.org/0000-0002-5356-4526. E-mail: meublesbjr@gmail.com
} 


\title{
THE IMPORTANCE OF THE PEDAGOGICAL POLITICAL PROJECT IN THE CONSTRUCTION OF THE CONTEXTUALIZED TEACHING-LEARNING PROCESS: a case study of CEFFA Manoel Monteiro
}

\begin{abstract}
The text, critically analyzes the Political Pedagogical Project - PPP of the Manoel Monteiro Alternation Training Center - CEFFA M. M., located in the Pau Santo community, in the municipality of Lago do Junco, in the state of Maranhão. This school works based on the pedagogy of the alternation, dividing its formative process between different times and spaces, that take place between the school institution and the young professional partner. Thus, the analysis is carried out seeking to understand how the process of contextualization of teaching is concretized in the teaching-learning processes, based on the orientation they have in the school's own PPP. In this sense, the objective of this work is to identify how CEFFA's pedagogical political project Manuel Monteiro articulates the pedagogical tools of alternation for the construction of the contextualized teaching-learning process. For this task, brief histories were built on the founding of the school and the pedagogical method of alternation, in order to situate the reader in the geographical, historical and social context of the work and in the contribution generated by the pedagogy of alternation, to the contextualization process of teaching in the school. In addition, the process of formation was analyzed, taking as basis the three categories of the process of contextualization of science education. Thus, the work is organized in introduction, methodology, results and discussions, final considerations and bibliographical references.
\end{abstract}

Keywords: Alternation Pedagogy. Democratic Management. Contextualization of Teaching.

\section{LA IMPORTANCIA DEL PROYECTO POLÍTICO PEDAGÓGICO EN LA CONSTUCCIÓN DEL PROCEDIMIENTO DE ENSEÑANZA-APRENDIZAJE CONTEXTUALIZADO: un estudio de caso del CEFFA Manoel Monteiro}

\section{RESUMEN}

El texto, analiza críticamente el Proyecto Político Pedagógico - PPP de la escuela Centro Familiar de Formación por Alternancia Manoel Monteiro - CEFFA M. M., ubicada en la comunidad Pau Santo, municipio de Lago do Junco, estado de Maranhão. Esta escuela funciona basada en la pedagogía de la alternancia, dividiendo su proceso formativo entre tiempos y espacios distintos, que se efectúan entre la institución escolar y el medio socio profesional de los jóvenes. Así, el análisis se realiza buscando comprender cómo el proceso de contextualización de la enseñanza se concreta en los procesos de enseñanza-aprendizaje, tomando como base la orientación que disponen en el propio PPP de la escuela. En este sentido, el trabajo tiene como objetivo identificar cómo el proyecto político pedagógico de la CEFFA Manuel Monteiro articula los instrumentos pedagógicos de la alternancia 
para la efectivación de la construcción del proceso de enseñanza-aprendizaje contextualizado. Para esta tarea, se construyó breves históricos sobre la fundación de la escuela y el método pedagógico de la alternancia, para situar al lector en el contexto geográfico, histórico y social del trabajo y en la contribución generada por la pedagogía de la alternancia, al proceso de contextualización de la enseñanza en la escuela. También, se analizó el proceso de formación, tomando como base las tres categorías del proceso de contextualización de la enseñanza de ciencias. Así, el trabajo está organizado en introducción, metodología, resultados y discusiones, consideraciones finales y referencias bibliográficas.

Palabras clave: Pedagogía de la Alternancia. Gestión Democrática. Contextualización de la Enseñanza.

\section{INTRODUÇÃO}

Na década de 80 surge o termo Projeto Político-Pedagógico (PPP) se contrapondo "à visão burocrática e técnica do planejamento educacional" (ARAÚJO, 2010, p. 68). A partir da década de 1990, a proposta de criação de um documento norteador dos processos de formação empregados em uma instituição de ensino, o PPP, começa a ser amplamente discutida e difundida em grande parte das instituições de ensino do Brasil.

O termo projeto, tem origem etiológica e derivação da palavra projectu, que é o particípio passado do verbo projecere, que significa lançar para diante (ARAÚJO, 2010). Esses termos sugestionam a ideia de movimento, ou mesmo, de planejamento constante sobre uma determinada realidade para melhorá-la em um futuro próximo. No caso do PPP, refere-se especificamente à realidade escolar. Assim, o PPP, é uma forma de se planejar as ações pedagógicas no meio educativo (PASSAMAI, 2010).

Sendo o PPP, um instrumento norteador de todos os processos de formação empregados por uma instituição escolar, como orienta a lei $n^{\circ} 9$. 394/96, deve ser também a fonte orientadora do processo de contextualização do ensino. Esse processo, deve ser compreendido, como uma abordagem metodológica de ensino que contribui para o processo de significação dos conteúdos, ao envolver aspectos da realidade concreta dos estudantes no processo de ensino-aprendizagem, tornando-o mais significativo. 
Há como pressuposto para ocorrer a construção do aprendizado, o necessário estabelecimento de relações e interações entre sujeito e objeto do conhecimento, sendo a contextualização uma abordagem fundamental. Nesse sentido, a pedagogia da alternância pode contribuir para o processo de contextualização dos conteúdos por considerar em seus processos de formação os conhecimentos prévios dos estudantes, ao mesmo tempo, em que estabelece relações e interações, entre o conhecimento científico e as realidades cotidianas de vida dos sujeitos em formação.

Dessa forma, a escola Centro Familiar de Formação por Alternância Manoel Monteiro - CEFFA M. M. toma como base fundamental para seu PPP e todos os processos de formação, a pedagogia da alternância. Nesse sentido, a escola utiliza de diferentes instrumentos pedagógicos para conhecer a realidade de vida dos estudantes e envolvê-la no processo de ensino-aprendizagem contextualizado. Assim, o objetivo deste trabalho é identificar como o projeto político pedagógico da escola CEFFA M. M. articula os instrumentos pedagógicos da alternância para a efetivação da construção do processo de ensino-aprendizagem contextualizado. Assim, o trabalho está organizado em resumo, introdução, metodologia, desenvolvimento, considerações finais e referências.

\section{METODOLOGIA}

O trabalho apresenta discussões sobre o PPP embasado nos trabalhos de Araujo (2010), Passamai (2010), SEDUC (2015), Cruz et al. (2015) e Veiga (2009). Pedagogia da Alternância, embasado nos trabalhos de Oliveira (2011), Trindade (2011), Gimonet (2007), Marirrodriga (2010), Silva (2012), Vergutz (2012), Nosella (2014), Nawroski (2012), Ribeiro (2008), Moro et al. (2007) e Teixeira (2008). Contextualização do ensino, fundamentado nos trabalhos de Kato e Kawasaki (2011), Favila e Andaime (2013), Silva e Marcondes (2010), Wartha, Silva e Bejarano (2013), Santos (2007) e Silva (2014). Utiliza-se ainda, das orientações oficiais como a Lei $n^{\circ} 9.394 / 96$, dos Parâmetros Curriculares Nacionais - PCNs (1997; 1998; 2000) e das Diretrizes Curriculares Nacionais - DCN (2003). 
Nesse sentido, partiu-se da perspectiva de um estudo teórico, baseado no método de abordagem dialético. O estudo teórico busca discutir e rediscutir, construir e reconstruir teorias e conceitos, não estando voltado para uma intervenção direta na realidade (DEMO, 1994). Já o método dialético é considerado a "arte do diálogo", visto que etimologicamente significa diá (através) e Logos (discurso, linguagem).

Segundo Gil (2008) o termo dialético é muito antigo, sendo utilizado ainda pelo filósofo matemático Platão, na Grécia antiga, no sentido da "arte do diálogo", assim como mencionado. Segundo Engles (1974) apud Gil (2008, p. 13) "o materialismo dialético pode, pois, ser entendido como um método de interpretação da realidade, que se fundamenta em três grandes princípios", a saber: 1. A unidade dos opostos; 2. Quantidade e qualidade; e 3. Negação da negação. Assim, segundo Gil (2008), o método dialético fornece as bases para uma compreensão da realidade de forma dinâmica e totalizante, no sentido de que reconhece que os fatos sociais não podem ser estudados ou entendidos quando abordados de forma isolada, abstraídos de suas influências sociais, culturais, políticas, econômicas e etc.

Nesse sentido o PPP da CEFFA M. M. é discutido com relação à qualidade dos processos de formação dos estudantes e dos instrumentos pedagógicos contidos nele. Esses processos e instrumentos são analisados em seu contínuo movimento na caminhada desse processo de formação, não como partes isoadas, mas interdependentes, dentro da totalidade do PPP e da situação existêncial do ambiente rural e dos sujeitos que vivem nele e a partir dele, na qual a CEFFA M. M. se insere.

Foram utilizadas como técnicas e instrumentos de observação indireta a consulta bibliográfica (MARCONl; LAKATOS, 2003) dos referenciais já citados, referentes às temáticas em discussão. Dessa forma, optou-se por construir um breve histórico sobre o processo de fundação da escola, para situar o leitor no contexto geográfico, histórico e social do trabalho. Posteriormente, construiu-se também um breve histórico sobre a pedagogia da alternância, para situar o leitor no que se refere ao surgimento desta, 
assim como, para fundamentar a discussão sobre a importância desta pedagogia, no processo de contextualização do ensino.

Como instrumento investigativo de observação direta, utilizou-se o PPP da CEFFA M. M. realizando-se discussões sobre como o PPP da escola orienta - processo de contextualização do ensino, utilizando de diferentes instrumentos pedagógicos da alternância, e verificando em qual ou quais das categorias do processo de contextualização descritas por Favila e Andaime (2013) e Silva (2007), este instrumento pode favorecer a contextualização do ensino.

As três categorias do processo de contextualização do ensino adotadas são: $1^{\circ}$ Como exemplificação pontual de fatos do cotidiano e de caráter motivacional; $2^{\circ}$ Como estratégia de ensino-aprendizado do estudo científico de situações, fatos ou fenômenos; e $3^{\circ}$ Como estudo de questões sociais para a formação de cidadão crítico na tomada de decisões (FAVILA e ANDAIME, 2013; SILVA, 2007).

Também, foram realizadas visitas à escola e rodas de conversa com os alunos $e$ os professores para verificar se realmente os instrumentos pedagógicos informados no PPC aconteciam, além de diálogos com o diretor da escola e membros da Associação do Centro Familiar de Formação por Alternância de Ensino Médio e Profissionalizante - ACEMEP, para verificar o processo de fundação da escola e construção do PPC.

\section{HISTÓRICO DE CRIAÇÃO DO CENTRO FAMILIAR DE FORMAÇÃO POR ALTERNÂNCIA - CEFFA MANOEL MONTEIRO}

O CEFFA M. M. é resultado de uma mobilização de agricultores familiares, lideranças comunitárias, sindicais, associações, pessoas e entidades comprometidas e preocupadas com 0 desenvolvimento Sustentável do Estado do Maranhão. As organizações e movimentos sociais que contribuíram para a fundação dessa escola, foram a Associação Comunitária de Educação em Saúde e Agricultura - ACESA, Animação dos Cristãos no Meio Rural - ACR, Comissão Pastoral da Terra - CPT, União das Associações de Escolas de Famílias Agrícolas no Maranhão - UAEFAMA, 
Associação Regional das Casas Familiares Rurais - ARCAFAR, Associação da Escola Família Agrícola de Lago do Junco - AEFALJ e Sindicato dos Trabalhadores e Trabalhadoras Rurais - STTR de Lago do Junco e Lago da Pedra.

Estas organizações e movimentos sociais, formaram comissões para criar o estatuto da Associação do Centro Familiar de Formação por Alternância de Ensino Médio e Profissionalizante - ACEMEP, sendo esta, fundamentada em estatutos de Escolas Famílias Agrícolas - EFAs, já existentes. A associação foi fundada em junho de 2005, passando a gerir a escola no ano de 2006, mesmo ano em que inicia suas aulas com uma turma de 27 alunos.

A escola CEFFA M. M., está localizada geograficamente na região do Médio Mearim, comunidade Pau Santo, município Lago do Junco - MA, aproximadamente $290 \mathrm{~km}$ da capital São Luís. O CEFFA M. M., está inserido em uma propriedade de 100 hectares doadas por associações comunitárias circunvizinhas. A escola é mantida através de entidades estrangeiras, principalmente alemãs. No entanto, tem uma parceria com o governo do Estado do Maranhão para o pagamento dos professores. Ressalta-se, que apesar de realizar uma parceria com o governo, a escola tem autonomia para gerir seus processos de organização a partir da associação ACEMEP.

Segundo a ACEMEP (2016), a implantação do CEFFA M. M. foi devido não existir nenhuma instituição de ensino em nível médio que adotasse a pedagogia da alternância e contribuísse para o desenvolvimento rural sustentável, atendendo aos discentes egressos de EFAs de vários municípios e oriundos de áreas de assentamentos, quilombolas e etc. Nesse sentido, esta escola surgiu como uma forma de tentar resolver o histórico problema da educação no meio rural, trazendo uma alternativa de ensino médio profissionalizante adequado a realidade da região.

De acordo com o $\S 1^{\circ}$ do Art. $1^{\circ}$ da LDB, a educação deverá vincularse ao mundo do trabalho e à prática social (BRASIL, 1996). Para tanto, a escola foi embasada na Pedagogia da Alternância para realizar a formação dos estudantes. Uma pedagogia que segundo Oliveira (2011), é uma forma 
de educar que não separa o mundo da escola do universo do trabalho, da família e da comunidade, pois se estabelece de maneira dialética a todas. Logo, realiza-se através de uma inter-relação dialética entre os dois campos construindo uma formação integral e contextualizada para os sujeitos do campo (TRINDADE, 2011).

\section{BREVE HISTÓRICO DA PEDAGOGIA DA ALTERNÂNCIA}

A pedagogia da alternância, é uma alternativa pedagógica que tem origem na França a partir de meados da década de 1930 (GIMONET, 2007; MARIRRODRIGA, 2010). Essa pedagogia, surge como uma forma de organização metodológica do processo de formação dos sujeitos do campo, em diferenciação ao modelo de organização tradicional da educação francesa, especificamente a efetuada no campo. Assim, esta nasce para considerar e dar conta dos processos cotidianos de vivência dos sujeitos do campo, garantindo-lhes o direito de estudar sem sair de suas origens, ao vincular ensino formal com trabalho produtivo no campo, garantindo também uma educação contextualizada.

Assim sendo, Gimonet (2007), afirma que os sujeitos que promoveram as primeiras iniciativas para a fundação do método pedagógico da alternância, estavam preocupados com o futuro que teriam os seus filhos. Em virtude desta inquietação, um grupo de sujeitos, dos quais se destaca como atores principais o agricultor Jean Peyrat, o jovem camponês Yves Peyrat e o padre Granereau da igreja católica francesa (GIMONET, 2007; MARIRRODRIGA, 2010), dão início a pedagogia da alternância.

Assim, como se pode observar, o período histórico de criação da pedagogia da alternância, se estabelece entre as duas grandes guerras mundiais, onde a França se encontrava em uma situação muito difícil, sendo fundamental a sua reconstrução econômica e social (SILVA, 2012). Essa seria a problemática geral, mas nos interessa muito mais o contexto agrário do país, já que a pedagogia da alternância tem origem no campo. Assim, não diferente do contexto agrário historicamente configurado nas sociedades, sobretudo ocidentais, o contexto rural francês, também se encontrava em 
abandono, principalmente no que se refere ao processo educacional. 0 Estado francês apoiava essencialmente uma educação urbanista, em detrimento da educação dos povos do campo (SILVA, 2012).

Essa situação histórica, contribuía para a construção de um movimento crescente de êxodo rural, embasado nas más condições de vida e educação dos povos do campo, fortalecendo um modelo de sociedade que colocava em destaque a cidade (VERGUTZ, 2012; NOSELLA, 2014). Essa configuração social, também contribuía com um crescente desanimo dos jovens camponeses por uma escola urbanista, que não os considerava em seu território concreto de existência e produção de vida, o Campo.

Desse modo, a pedagogia da alternância, se origina não somente, no cerne de um conjunto de dificuldades, problemáticas e questionamentos, mas principalmente, na resistência camponesa ao modelo de educação adotado nesse momento histórico, no território francês. Destaca-se então, a situação histórica que representaria a criação da pedagogia da alternância, quando o filho de um camponês demonstra ao seu pai, um certo desinteresse por uma escola que não valorizava e muito menos fazia referência ao contexto e a origem dos sujeitos do campo (NAWROSKI, 2012).

Nesse contexto educacional francês, os jovens $e$ as famílias camponesas se encontravam frente a um cruel dilema. Era necessário optar entre "estudar ou parar o processo de escolarização". Dar continuidade aos estudos significava sair do campo pela falta de escolas, se direcionando necessariamente para a cidade, correndo risco assim, de perder os vínculos com cultura camponesa, a família e a terra. De outro modo, parar de estudar, garantiria a continuidade do jovem no campo, trabalhando em atividades agrícolas junto a sua família (SILVA, 2012).

Alinhado a essa discussão, estaria a necessidade que as famílias camponesas tinham da mão de obra de seus filhos, na realização de suas atividades de produção das condições materiais de existência. Considera-se ainda, que pouquíssimas famílias tinham condições suficientes para colocar seus filhos em escolas na cidade, pois também se fazia necessário assegurar 
condições como alimentação e moradia na zona urbana, para seus filhos (SILVA, 2012).

Assim sendo, a pedagogia da alternância se origina sobretudo, como uma alternativa metodológica de formação na educação formal, embasada nas especificidades do ambiente rural e dos sujeitos que vivem nele e a partir dele. Trindade (2011), considera que apesar das inúmeras dificuldades e empecilhos ao processo de escolarização dos sujeitos do campo, a pedagogia da alternância é fundada como uma nova alternativa pedagógica, capaz de possibilitar aos jovens do campo estudar e trabalhar junto as suas famílias. Além disso, garante a produção das condições materiais de existência, ao mesmo tempo, em que também garante a consideração e valorização das especificidades territoriais, econômicas e culturais a partir de uma educação contextualizada.

Nessa perspectiva, essa alternativa pedagógica buscava a consolidação de uma formação integral, tendo como ponto de partida uma instituição escolar, que reconhecesse as especificidades camponesas e do seu território de existência, desde o processo pedagógico (NAWROSKI, 2012).

Assim, com o passar dos tempos e com a efetivação de experiências baseadas na pedagogia da alternância, foi fundada a primeira "Maisons Familiales Rurales na comunidade rural Sérignac-Péboudou, em Lot-etGarone, no sudoeste da França" (TRINDADE, 2011, p. 260), que utilizava da pedagogia da alternância como metodologia para a formação dos sujeitos envolvidos.

Esta experiência de formação foi se expandindo, e no ano de 1945, ocorreu um processo de ampliação desta para a África, Europa e Oceania (RIBEIRO, 2008). Somente em 1969, por meio do Movimento de Educação Promocional do Espírito Santo - MEPES, a pedagogia da alternância chega ao Brasil (TEIXEIRA, 2008; RIBEIRO, 2008; NOSELLA, 2014). Observa-se, que o momento histórico em que esta pedagogia chega no país, coincide com o período de vigência do regime militar (1964-1985). Existe uma certa semelhança da realidade brasileira em 1969 com a realidade francesa nos primórdios da pedagogia da alternância. Durante a ditadura militar, as 
políticas públicas no Brasil eram intensamente direcionadas à produção agropecuária em larga escala, voltadas ao mercado externo, vinculada à implantação de tecnologias no meio rural, contribuindo com o êxodo dos sujeitos do campo para a zona urbana (MORO et al., 2007).

\section{PROJETO POLÍTICO PEDAGÓGICO COMO INSTRUMENTO DE CONTEXTUALIZAÇÃO DO ENSINO NO CEFFA MANOEL MONTEIRO}

O PPP é o instrumento orientador de todas as instituições de ensino, devendo "estabelecer as intenções e estratégias para o processo pedagógico a ser desenvolvido na escola", sendo responsabilidade dessas instituições promoverem a elaboração e a execução deste, conforme Art. 12, da Lei no 9.394/96 (SEDUC, 2015, p.25). Essa orientação oficial, está embasada na perspectiva de que a instituição de ensino tem o dever de tomar para si, como uma tarefa essencial, o trabalho de planejar, discutir e refletir sobre sua intencionalidade educativa (VEIGA, 2009).

Sendo o PPP o documento norteador dos processos de ensinoaprendizagem de uma escola, é também a fonte orientadora de todo o processo de formação realizado no CEFFA M. M. Nesse sentido, é necessário enfatizar que o plano de formação da escola, contido no PPP, está baseado na Pedagogia da Alternância e na utilização de seus instrumentos pedagógicos. A pedagogia da alternância visa a formação integral, contribuindo para o desenvolvimento pessoal dos estudantes, além do desenvolvimento regional sustentável, pela atuação destes em seus meios de convivência.

De acordo com o PPP do CEFFA M. M. (ACEMEP, 2012, p. 3), para alcançar seus objetivos principais "formação integral da pessoa" e o "desenvolvimento Rural Sustentável", dois dos objetivos do PPP, o CEFFA M. M. utiliza dos seguintes instrumentos: "Associação como princípio de participação e envolvimento das famílias na gestão do Projeto Educativo; e a Pedagogia da Alternância como metodologia, valorizando os conhecimentos empíricos dos discentes". 
Assim, pode-se observar que o CEFFA M. M. busca garantir a participação e o envolvimento dos pais e/ou responsáveis dos estudantes na gestão da escola, enfatizando a importância de todos os envolvidos na construção e gestão participativa do próprio PPP da escola (CRUZ et al., 2015). Dessa forma, o CEFFA M. M. garante, reconhece e valoriza as experiências de vida desses sujeitos no planejamento pedagógico da escola, o que facilita a idealização de ferramentas metodológicas visando o processo de ensino-aprendizagem contextualizado.

No que diz respeito a utilização da pedagogia da alternância como metodologia adequada para a formação dos sujeitos envolvidos, deve-se considerar, que essa pedagogia realiza um processo de alternâncias entre tempos e espaços distintos no processo de formação. Esses espaços, se dão entre a instituição de ensino e o meio socioprofissional do jovem, sendo classificados em Tempo Escola - TE e Tempo Comunidade - TC (RIBEIRO, 2008; NOSELLA, 2014).

Essa alternância, entre tempos e espaços distintos de formação, proporciona a valorização dos conhecimentos empíricos pela consideração dos conhecimentos advindos dos contextos de existência dos estudantes, pois o que buscam é a solução dos problemas apresentados pelos alunos. De acordo com ACEMEP (2016, p. 05), deve-se considerar ainda que:

Na Pedagogia da Alternância a ação educativa não está vinculada à mera transmissão dos conhecimentos, mas a operacionalização de pesquisas, e experimentações práticas considerando a experiência do cotidiano, matéria prima para tornar a aprendizagem dinâmica, contextualizada e interessante, numa conjugação de vários atores: jovens como principais sujeitos, pais, professores, comunidades, famílias, lideranças, orientadores de estágios e entidades afins. A mesma acredita na experiência coletiva como elementos da aprendizagem, crítica e dialética.

Dessa forma, o meio socioprofissional do jovem é considerado como o ponto de partida e de chegada do processo de ensino-aprendizagem, possibilitando assim, uma educação contextualizada. Nesse sentido, segundo a ACEMEP (2016, p. 03): 


\begin{abstract}
A Pedagogia da Alternância proporciona uma estreita ligação entre escola e família, ou melhor, trabalho-estudo-trabalho, ação-reflexãoação, faz com que o aluno contextualize sua realidade de vida através de instrumentos pedagógicos específicos. Os conteúdos tratados no processo educacional fluem através de "canais" que conjugam o saber do censo comum com o saber histórico social e o cientifico. O ensino é vivo, histórico, experimental e cientifico.
\end{abstract}

Assim, como pode ser observado, a pedagogia da alternância aproxima a escola e o contexto cotidiano do estudante, criando um vínculo e um círculo contínuo entre trabalho-estudo-trabalho pela efetivação dos tempos e espaços distintos do processo de formação (TE e TC). Nessa perspectiva, o CEFFA M. M. tem a possibilidade de criar um processo de ação-reflexão-ação, fazendo com que o ensino seja realizado de maneira contextualizada, ao envolver as experiências concretas de vida dos estudantes no espaço escolar e nos conteúdos curriculares de ensino.

Nesse contexto, o plano de formação da escola está baseado em duas lógicas principais:

Uma representada pela experiência de vida dos jovens, suas atividades e responsabilidades familiares, sociais dentro do ambiente local e regional (conteúdos vivenciais) e a outra constituída dos aspectos escolares formais, subordinados aos "controles" sociais externos à instituição escolar (ACEMEP, 2016, p. 08).

A primeira lógica, se refere às experiências concretas de vida dos estudantes em suas realidades, que é considerada graças a essência metodológica da alternância. Nessa lógica, a contextualização do ensino pode e deve ocorrer por meio das três categorias de contextualização: $1^{\circ}$ Como exemplificação pontual de fatos do cotidiano e de caráter motivacional; $2^{\circ}$ Como estratégia de ensino-aprendizado do estudo científico de situações, fatos ou fenômenos; e $3^{\circ}$ Como estudo de questões sociais para formação de cidadão crítico na tomada de decisões (FAVILA; ANDAIME, 2013; SILVA, 2007). 


\section{PRINCIPAIS INSTRUMENTOS PEDAGÓGICOS UTILIZADOS PARA A CONTEXTUALIZAÇÃO DO ENSINO DO CEFFA MANOEL MONTEIRO}

O PPP da escola, tem sua linha pedagógica fundamentada nos instrumentos pedagógicos da alternância. Assim, utiliza-se principalmente dos seguintes instrumentos no processo de formação:

Planos de Estudo, Colocação em Comum, Caderno da Realidade, Viagens e Visitas de Estudo, Intervenções Externas, Cadernos Didáticos, Atividades Retorno e Experiências, Projeto Profissional do Jovem, Visitas às Famílias, Estágios e Avaliações (ACEMEP, 2016, p. 06).

Baseada nesses instrumentos pedagógicos, a escola trabalha com três passos principais na formação dos estudantes: $1^{\circ}$ Ver (conhecimento prévio); $2^{\circ}$ Refletir (aprofundamento teórico); $3^{\circ}$ Atuar (Proposta de Ação) (ACEMEP, 2016, p. 10). Esses três passos são realizados graças a execução dos instrumentos pedagógicos da alternância, e se apresentam como ferramentas facilitadoras do processo de contextualização a ser efetuado na escola, ao mesmo tempo em que se considera o que é indicado pelas orientações oficiais da LDB, PCNs e DCNs (BRASIL, 1996, 2000, 2013).

O $1^{\circ}$ passo "Ver" (conhecimento prévio), se dá em um processo de investigação desenvolvido por professores e alunos, sobre a realidade comunitária ou socioprofissional dos estudantes. Nesse sentido, é preciso considerar que a escola trabalha com o ensino médio integrado ao curso técnico profissionalizante em agropecuária, atendendo a estudantes de diferentes municípios e regiões do estado do Maranhão. Essa distribuição geográfica dos estudantes, dificulta $\circ$ processo de investigação e conhecimento das realidades dos alunos, para poder utilizá-la no processo de ensino-aprendizagem de forma contextualizada.

No entanto, o CEFFA M. M. utiliza dos instrumentos pedagógicos "Plano de Estudo - PE" e "Visita às Famílias" para conhecer a realidade concreta e cotidiana dos estudantes (GIMONET, 2007). Essa investigação da realidade concreta dos estudantes ocorre de forma conjunta, no sentido de que, tanto professores como alunos são pesquisadores desta realidade. Assim, a partir 
do uso do plano de estudo, utilizado como um instrumento de pesquisa efetivado pelos estudantes, a escola consegue conhecer as principais questões do contexto de vivência dos alunos. Para tanto, a escola propõe aos estudantes, questões centrais de pesquisa na comunidade ou meio socioprofissional, como questões sociais, econômicas, culturais e ambientais.

Esse instrumento pedagógico, garante a apreensão da realidade concreta dos alunos pela escola, contribuindo para a realização de um processo de ensino-aprendizagem contextualizado, além de tirar o estudante da condição de sujeito passivo nesse processo. Portanto, nesse processo o jovem em formação não é só um simples estudante, mas também um pesquisador sobre sua própria realidade. Nesse sentido, Paulo Freire (1987) já dizia, que ninguém melhor que os próprios sujeitos para conhecerem a si mesmos e contribuírem com o processo de transformação de suas realidades.

Depois de realizada a pesquisa, o estudante também faz a sistematização e apresentação dos dados pesquisados, através do instrumento pedagógico "Colocação em Comum". O estudante apresenta tanto para os demais colegas, quanto para os professores responsáveis, o resultado de sua pesquisa, tornando conhecida todas as principais questões de sua realidade concreta. Esses dados servem como base para o processo de contextualização do ensino, já que é uma das formas dos professores conhecerem a realidade dos estudantes, que residem em diferentes regiões do estado do Maranhão.

De posse das informações do instrumento pedagógico "Colocação em Comum", o professor pode agora vivenciar essa realidade, relatada pelos alunos, por meio do instrumento pedagógico "Visita às Famílias", conhecendo in loco o contexto familiar e comunitários dos alunos. Assim, o professor pode atuar, no processo ensino-aprendizagem, a partir das experiências concretas de vida do aluno utilizando elementos, fatos e fenômenos de sua realidade.

O $2^{\circ}$ passo do processo de aprendizagem "Refletir" (aprofundamento teórico), busca a formação de um estudante capaz de reconhecer o meio 
em que está inserido e, a partir do processo de reflexão, ter uma visão melhorada da realidade, podendo intervir com uma proposta de ação $\left(3^{\circ}\right.$ Passo). Assim, considera-se que a partir do conhecimento adquirido na investigação por meio do Plano de Estudo e das Visitas às Famílias, os estudantes apoiados com o aporte teórico/prático científico da formação profissional dos professores, realizam um processo de reflexão sobre suas realidades concretas.

Portanto, com o aporte teórico/prático científico, o reconhecimento e a consideração dos conhecimentos advindos da realidade concreta dos educandos, no processo de ensino-aprendizagem contextualizado, a escola pode efetivamente contribuir para a formação de um cidadão críticoreflexivo, capaz de propor soluções para os problemas enfrentados no seu dia a dia. Essa lógica do Plano de Formação do PPP do CEFFA M. M. vai ao encontro de Brasil (1997), que destaca como um dos objetivos do processo de ensino-aprendizagem, que os alunos possam, nas diversas situações vividas, apresentar um posicionamento crítico-reflexivo, responsável e construtivo, praticando o diálogo como instrumento na resolução de conflitos em decisões coletivas.

Além disso, segundo os PCN's esse processo de ensino-aprendizagem deve levar o aluno a atuar como agente transformador na melhoria do seu ambiente. Nesse sentido, o CEFFA M. M. também contribui para o processo de tomada de decisões pelos estudantes, por meio da elaboração e execução do instrumento pedagógico "Projeto Profissional do Jovem - PPJ". Portanto, ao partir das experiências concretas dos alunos, o CEFFA M. M. encaminha um processo de ensino-aprendizagem favorável à concretização dos objetivos propostos pelos PCNs.

O PPJ é um instrumento elaborado pelos estudantes, em seu terceiro e último ano no CEFFA M. M., orientado pelos professores responsáveis. Com o PPJ, os estudantes são desafiados a elaborarem uma proposta de intervenção em sua realidade concreta de vida. Eles mesmos propõem, um projeto visando a melhoria da qualidade de vida da família, podendo também se estender à sua comunidade. Para isso, o estudante precisa 
utilizar de diferentes formas e fontes de informações e áreas do conhecimento, das quais vivenciou e ainda encontra-se vivenciando no seu processo de formação na escola.

Como é um projeto científico, que é apresentado para uma banca examinadora, precisa tomar como base o rigor do método científico e dos conhecimentos científicos, sem perder de vista, é claro, a necessidade e adaptabilidade desses conhecimentos à sua realidade cotidiana. Nesse entendimento, o estudante é conduzido a sair de uma postura passiva diante de suas questões existenciais, se tornando autor consciente e proativo de sua própria história, pela possibilidade que tem de criar e executar uma proposta de intervenção em sua realidade. Assim, este projeto, concretiza o $3^{\circ}$ passo do processo de aprendizagem "Atuar" (Proposta de Ação), orientado pelo PPP da escola.

\section{O PROJETO POLÍTICO PEDAGÓGICO E A ABORDAGEM DAS TRÊS CATEGORIAS DE CONTEXTUALIZAÇÃO DO ENSINO DE CIÊNCIAS}

Os trabalhos de Kato e Kawasaki (2011), Favila e Andaime (2013), Silva e Marcondes (2010), Wartha, Silva e Bejarano (2013), Santos (2007), e Silva (2014) discutem sobre o processo de contextualização do ensino de ciências, assim como, apresentam discussões sobre as orientações oficiais em relação a contextualização do ensino. Assim, estes autores, apesar de utilizarem de diferentes argumentos, congregam acerca de três categorias principais do processo de contextualização do ensino de ciências. Primeiro, como exemplificação pontual de fatos do cotidiano e de caráter motivacional; segundo, como estratégia de ensino-aprendizado do estudo científico de situações, fatos ou fenômenos; e terceiro, como estudo de questões sociais para a formação de cidadão crítico na tomada de decisões.

Essas categorias do processo de contextualização do ensino de ciências podem ser mais simples ou mais complexas, de acordo com a sequência lógica crescente em que estão apresentadas. Assim, a primeira categoria é a mais simples e também mais utilizada, pelo fato de apresentar 
- cotidiano do estudante apenas como uma exemplificação pontual no ensino (FAVILA; ANDAIME, 2013). A segunda categoria é utilizada como estratégia de ensino-aprendizagem, e se dispõe a utilizar o cotidiano do aluno para facilitar a compressão do conhecimento científico, se direcionando para o começo de uma reflexão crítica dos estudantes, sobre os temas em estudo (SILVA, 2014). Já a terceira categoria do processo de contextualização, é a mais complexa, pois busca o entendimento de questões científicas e tecnológicas em conjunto com os aspectos políticos, sociais, culturais, econômicos e ambientais de maneira mais crítica, tendo em vista a formação de um estudante capaz de dialogar e tomar decisões referentes às questões que envolvam a sua comunidade (FAVILA; ANDAIME, 2013).

Nesse sentido, assim como as três categorias de contextualização do ensino de ciências, os três passos de aprendizagem mencionados no PPP da escola, seguem uma sequência lógica de aprendizagem de acordo com a complexidade de cada passo. Nessa perspectiva, a primeira categoria de contextualização que apresenta a realidade do estudante como exemplificação, apesar de simples, é realizada graças a execução dos instrumentos pedagógicos denominados de Plano de Estudo - PE e de Visitas às Famílias.

Assim sendo, a partir da utilização destes instrumentos, o professor tem como conhecer o cotidiano de cada aluno, podendo envolvê-lo em suas práticas pedagógicas cotidianas. Isto porque, estes instrumentos são formas de conhecer a vida familiar e comunitária dos estudantes (contexto e realidade), levantando questões sociais, econômicas e culturais de suas realidades concretas para o processo de ensino, tornando a aprendizagem mais significativa.

Segundo Ausubel (1963), a aprendizagem é muito mais significativa à medida que o novo conteúdo é incorporado às estruturas de conhecimento do aluno, e adquire significado para ele a partir da relação com seu conhecimento prévio. Ou seja, a partir do momento em que o professor realiza o processo de contextualização do ensino, envolvendo a realidade 
concreta do educando com o conhecimento científico, o estudante passa a compreender que o conhecimento científico faz parte também de sua realidade, se tornando mais interessado pelos temas em estudo e, tendo uma aprendizagem mais significativa, conforme explicita a teoria de Ausubel.

O segundo passo de aprendizagem dialoga com a segunda categoria de contextualização, pois esse passo propõe uma reflexão conjunta realizada a partir do conhecimento que se dispõe da realidade e do aprofundamento teórico, sendo um aprofundamento baseado no conhecimento científico. Esse processo, é realizado também, tomando como base o conhecimento sobre a realidade dos estudantes, adquirido a partir do PE e das Visitas às Famílias.

No entanto, esse passo deve ir além do apenas pesquisar ou mencionar o cotidiano do estudante, como é o caso da primeira categoria do processo de contextualização. Deve ser realizada, uma reflexão sobre a realidade concreta dos estudantes envolvendo professores e alunos. Assim, é possível reconhecer e considerar o cotidiano do educando no processo de ensino-aprendizagem, de forma que o professor enquanto mediador do processo de formação dos estudantes, envolve e discute junto aos alunos o conhecimento científico e a sua relação com suas realidades concretas. Nessa perspectiva, a segunda categoria de contextualização seria então efetuada concretamente, pois esta é utilizada como uma estratégia de ensino-aprendizagem do estudo científico, pela utilização de situações fatos ou fenômenos das experiências concretas de vida dos estudantes (FAVILA; ANDAIME, 2013).

Já o terceiro passo do processo de aprendizagem, sugestiona uma posição mais atuante do aluno, ou seja, a partir do conhecimento adquirido e através do processo de reflexão e aprofundamento científico, realizados nos dois primeiros passos anteriores e nas duas primeiras categorias, o estudante terá para si, uma visão melhorada da realidade, devendo então construir uma proposta de ação, que é concretizada pela elaboração do PPJ. Essa orientação do PPP do CEFFA M. M., dialoga com as orientações 
oficiais dos PCNs (1997) volumes 3, 5, 8, 10 e ainda com as de 1998, que apontam para a formação de um estudante transformador de sua realidade, contribuindo para a melhoria desta.

A escolha do tema do PPJ como uma proposta de intervenção, bem como a metodologia científica a ser aplicada, devem ser adequadas a suas realidades, propondo-se uma intervenção positiva em suas comunidades e espaços de vivência, tendo em vista $\circ$ seu desenvolvimento socioeconômico. Portanto, esse terceiro passo do processo de formação dos estudantes contribui para a construção de uma responsabilidade social. Nesse sentido, a terceira categoria de contextualização, que busca a formação de um sujeito crítico, capaz de tomar decisões positivas perante a sociedade (FAVILA; ANDAIME, 2013), apesar de complexa, seria efetivada concretamente.

É preciso compreender que a terceira categoria do processo de contextualização do ensino de ciências, considera os aspectos sociais e culturais da ciência e da tecnologia, buscando o entendimento crítico e a formação de um estudante capaz de intervir em seus contextos sociais, políticos, econômicos, culturais e ambientais (SILVA, 2007). Nesse sentido, o PPJ além de ser uma proposta de intervenção, elaborado pelos próprios estudantes, e aplicados em suas realidades concretas de vida, é também uma forma de congregar e incorporar todo o conhecimento científico e tecnológico adquirido em seu processo de formação na escola. Dessa forma, a escola contribui para a formação de um estudante capaz de utilizar diversas tecnologias e fontes de informações, para além do acúmulo da informação, mas utilizando-ás na construção de novos conhecimentos e resolução de questões do cotidiano, empregando o pensamento lógico, a criatividade e a capacidade de analisar criticamente a realidade (PCN, 1997).

\section{CONSIDERAÇÕES FINAIS}

As reflexões realizadas durante o desenvolvimento do trabalho, permitem identificar e compreender como o processo de contextualização 
é orientado pelo PPP da escola, facilitando sua efetivação nos seus processos de ensino-aprendizagem. Nesse sentido, a escola tem seu plano de formação baseado em três passos principais: $1^{\circ}$ Ver (conhecimento prévio); $2^{\circ}$ Refletir (aprofundamento teórico); $3^{\circ}$ Atuar (Proposta de Ação) que orientam todos dos processos pedagógicos desenvolvidos, tanto por professores como pelos estudantes.

Compreende-se também, que esses três passos de aprendizagem mencionados no PPP da escola CEFFA M. M., podem ser concretizados graças a utilização dos instrumentos pedagógicos da alternância. Com o uso destes instrumentos, tanto professores quanto estudantes têm condições de conhecer o cotidiano de vivência de cada sujeito envolvido nos processos de formação da escola. Enquanto sujeito mediador do processo de ensinoaprendizagem, o educador tem condições de envolver a realidade concreta dos estudantes em suas aulas, por ser ele mesmo um pesquisador do cotidiano dos estudantes, através dos instrumentos pedagógicos "Visita às Famílias" e "Colocação em Comum".

Portanto, a escola CEFFA M. M. através da pedagogia da alternância e da utilização de seus instrumentos pedagógicos, orienta a realização da abordagem metodológica da contextualização, nos seus processos de ensino-aprendizagem. Isso porque, o PPP da escola orienta todos os processos de formação, que vão desde a pesquisa sobre a realidade concreta dos sujeitos, a reflexão teórica sobre essa mesma realidade, até a elaboração de uma proposta de intervenção pelos estudantes em suas realidades. Tomando como base e envolvendo o conhecimento científico para isso e tirando o estudante da condição de sujeito passivo e tornando-o ativo.

Nessa perspectiva, com a execução dos três passos do processo de ensino-aprendizagem, mencionados no PPP, a escola possibilita a concretização das três categorias do processo de contextualização do ensino de ciências, ao envolver e considerar a realidade concreta de vivência dos estudantes. O que chama a atenção, nesse entendimento, não é o simples fato da orientação ou direcionamento do PPP para o processo 
de contextualização, mas sim, o fato dos sujeitos serem "levados a fazer". Portanto, além de atuarem no espaço formal que é a sala de aula, os professores são levados a serem pesquisadores da realidade dos alunos e os alunos a serem sujeitos ativos da construção dessa realidade.

Portanto, o PPP com sua lógica do plano de formação dos estudantes possibilita um processo de ensino-aprendizagem contextualizado contribuindo para a formação de um cidadão crítico-reflexivo. Essa lógica do Plano de Formação do PPP do CEFFA M. M. vai ao encontro dos PCNs, que destacam a importância do aluno aprender a mobilizar competências para solucionar problemas em contextos apropriados, sendo capaz de transferir essa capacidade de resolução de problemas para os contextos do mundo social, apresentando um posicionamento crítico-reflexivo, responsável e construtivo, utilizando o diálogo como instrumento para a resolução de conflitos em decisões coletivas.

No entanto, o fato do professor conhecer a realidade do estudante não significa que ele realize um processo de ensino-aprendizagem contextualizado, apesar do processo de contextualização do ensino, ser uma abordagem fundamental para a significação dos conteúdos, tornando a aprendizagem mais significativa. Ou seja, é preciso que este projeto, seja mais do que um simples documento escrito com objetivos e metas a serem cumpridas pela comunidade escolar. Ele precisa ser a própria vivência cotidiana da escola.

\section{REFERÊNCIAS}

ACEMEP. Projeto político pedagógico. Centros de Formação Familiares por Alternância Manoel Monteiro. 2016.

ARAUJO, G. C. (2010). Escolas em Comunidades Campesinas: especificidades na construção do projeto político-pedagógico nas diferentes áreas do saber. In: DRAGO, R.; PASSAMAI, M. H.; ARAUJO, B. G. C. (Org.). Projeto político pedagógico da educação do campo. (p. 43-84), Universidade Federal do Espírito Santo, Espírito Santo: Biblioteca Central da Universidade Federal do Espírito Santo.

AUSUBEL, D. P. The psychology of meaningful verbal learning. New York: Grune and Stratton, 1963. 
BRASIL. Parâmetros Curriculares Nacionais. Brasília, 2000.

BRASIL. Parâmetros Curriculares Nacionais: Introdução. 1997. v. 1.

BRASIL. Lei № 9.394 de 20 de dezembro de 1996. Brasília, 1996.

BRASIL. Diretrizes Curriculares Nacionais da Educação Básica. Brasília, 2013.

BRASIL. Parâmetros Curriculares Nacionais: Terceiro e Quarto Ciclo do Ensino Fundamental. Brasília, 1998, v. 2.

BRASIL. Parâmetros Curriculares Nacionais: Matemática. Brasília, 1997, v. 3. BRASIL. Parâmetros Curriculares Nacionais: Apresentação dos Temas Transversais e Ética. Brasília, 1997, v. 8.

BRASIL. Parâmetros Curriculares Nacionais: Pluralidade Cultural e Orientação sexual. Brasília, 1997, v. 10.

BRASIL. Parâmetros Curriculares Nacionais: História e Geografia. V. 5.

FAVILA, M. A. C.; ADAIME, M. A contextualização no ensino de química sob a perspectiva cts: uma análise das publicações. Vidya, Santa Maria, v. 33, n. 2, p. 101-110, jun./jul. 2013. Disponível em:

https://www.periodicos.unifra.br/index.php/VIDYA/article/view/258/234.

Acesso em: 15/10/2017.

GIL, A. C. Métodos e técnicas de pesquisa social. 6. ed. São Paulo: Atlas. 2008.

GIMONET, J. C. Praticar e compreender a pedagogia dos CEFFAs. 1. ed. Petrópolis, RJ: Vozes, 2007.

KATO, D. S.; KAWASAKI, C. S. As concepções de contextualização do ensino em documentos curriculares oficiais e de professores de ciências. Ciência e Educação, São Paulo, v. 17, n. 1, p. 35-50, dez. 2011. Disponível em: http://www.scielo.br/pdf/ciedu/v17n1/03.pdf. Acesso em: 17/03/2017.

LOPES, A. C. Os parâmetros curriculares nacionais para o ensino médio e a submissão ao mundo produtivo: o caso do conceito de contextualização. Educação e Sociedade, Campinas, v. 23, n. 80, p. 386-400, set. 2002.

Disponível em: http://www.cedes.unicamp.br. Acesso em: 10/12/2016.

MARCONI, M. A.; LAKATOS, E. M. Fundamentos de metodologia científica. São Paulo: Editora Atlas S.A., 2003.

MARIRRODRIGA, R. G. Os CEFFA, uma iniciativa das famílias rurais: A primeira experiência de CEFFA no mundo. In: MARIRRODRIGA, R. G.: CALVÓ, P. P. (Org.). Formação em alternância e desenvolvimento local: o movimento educativo dos CEFFAs no mundo. Belo Horizonte: O lutador, 2010. AIDEFA p. 59-105. 
MORO, S. M. L.; LOPES, F. S.; MORO, I. L.; SANTOS, C. S.; JESUS, J. J. Pedagogia da alternância e escola família agrícola: proposta para promoção e o desenvolvimento rural. In: Encontro Latino Americano de Iniciação Científica e Encontro Latino Americano de Pós Graduação, 11, 2012, Paraíba.

Anais...Paraíba: Universidade do Vale do Paraíba, 2007, p. 3117-3120.

Disponível em:

http://www.inicepg.univap.br/cd/INIC_2007/trabalhos/humanas/epg/EPG00 039_050.pdf. Acesso em: 07/02/2016.

NAWROSKI, A. Aproximações da pedagogia da alternância com a escola nova. In: ANPED SUL, SEMINÁRIO DE PESQUISA EM EDUCAÇÃO DA REGIÃO SUL, 9, 2012, São Paulo. Anais... São Paulo: Universidade Federal de São Carlos, 2012. p. 1-14. Disponível em:

https://repositorio.ufsc.br/handle/123456789/94255. Acesso em: 07/02/2016.

NOSELLA, P. Origens da pedagogia da alternância no Brasil. 2. Ed. Vitória: Edufes, 2014.

OLIVEIRA, G. G. A pedagogia da alternância na escola família agrícola de

pinheiros - ES: os processos de territorialização desterritorialização e reterritorialização do campesinato e a relação campo - cidade. Monografia (Especialista em Educação) - Universidade Estadual Paulista "Júlio de Mesquita Filho". Presidente Prudente, 2011. Disponível em:

http://www2.fct.unesp.br/nera/monocegeo/monografia_gutemberg.pdf.

Acesso em: 02/12/2017.

PASSAMAI, M. H. Projeto-pedagógico como articulador do trabalho na escola (o ensino e a aprendizagem) e de integração entre a comunidade e a escola. Como pensar parcerias?. In: DRAGO, R.; PASSAMAI, M. H.; Araujo, B. G. C. (Org.). Projeto político pedagógico da educação do campo. Espírito Santo: Universidade Federal do Espírito Santo, 2010. p. 09-42.

PEREIRA, C. M.; KIILL, K. B. Contextualização no ensino de Química: Um olhar sobre a formação inicial. Investigação Qualitativa em Educação, Brasil, v. 2, n. 8, p. 49-53, jul. 2015. Disponível em:

https://proceedings.ciaiq.org/index.php/ciaiq2015/article/view/213/209. Acesso em: 12/10/2017.

SANTOS, W. L. P. Contextualização no ensino de ciências por meio de temas CTS em uma perspectiva crítica. Ciência \& Ensino, Brasil, v. 1, n. 2, p. 1-12, nov. 2007. Disponível em: http://files.gpeceausp.webnode.com.br/200000358-0e00c0e7d9/AULA\%206-\%20TEXTO\%2014\%20CONTEXTUALIZACAO\%20NO\%20ENSINO\%20DE\%20CIENCIAS\%20POR\%20M El.pdf. Acesso em: 15/07/2017.

SEDUC: Secretaria de educação do Estado do Maranhão. Caderno de Orientações pedagógicas: Gestão escolar. São Luís: SEDUC, 2015. 96 p. 
Disponível em: http://www.educacao.ma.gov.br/files/2017/05/apostila-finalproduc\%CC\%A7a\%CC\%83o.pdf. Acesso em: 03/10/2018.

RIBEIRO, M. Pedagogia da alternância na educação rural/do campo: projetos em disputa. Educação e Pesquisa, São Paulo, Vol. 34, Núm. 1, eneroabril, 2008, p. 27-45. Disponível em:

http://www.scielo.br/pdf/ep/v34n1/a03v34n1.pdf. Acesso em: 13/10/2016.

SILVA, L. H. As experiências de formação de jovens do campo: Alternância ou Alternâncias. Curitiba: Editora CRV, 2012.

TEIXEIRA, E. S.; BERNARTT, M. L.; TRINDADE, G. A. Estudos sobre Pedagogia da Alternância no Brasil: revisão de literatura e perspectivas para a pesquisa.

Educação e Pesquisa, São Paulo, v.34, n.2, p. 227-242, maio/ago. 2008. Disponível em: http://www.scielo.br/pdf/ep/v34n2/02.pdf. Acesso em: 13/10/2016.

SILVA, E. L. Contextualização no ensino de Química: ideias e proposições de um grupo de professores. 2007. 143 f. Dissertação (Mestrado) - Curso de Educação, Química Fundamental, Universidade de São Paulo, São Paulo, 2007. Disponível em:

http://www.educadores.diaadia.pr.gov.br/arquivos/File/marco2012/quimica _artigos/contex_ens_quim_dissert.pdf. Acesso em: 15/10/2017.

SILVA, E. L.; MARCONDES, M. E. R. Visões de contextualização de professores de química na elaboração de seus próprios materiais didáticos. Ensaio, Belo Horizonte, v. 12, n. 01, p. 101-119, jan. 2010. Disponível em:

http://www.scielo.br/pdf/epec/v12n1/1983-2117-epec-12-01-00101.pdf. Acesso em: 22/11/2017.

SILVA, R. T. et al. Contextualização e experimentação uma análise dos artigos publicados na seção "Experimentação no ensino de química" da Revista Química Nova na escola 2000-2008. Ensaio, Belo Horizonte, v. 22, n. 02, p. 277298, jun./dez. 2009. Disponível em:

http://www.scielo.br/pdf/epec/v1 1n2/1983-2117-epec-1 1-02-00277.pdf. Acesso em: 23/11/2017.

TRINDADE, D. R. A alternância como elo articulador na formação de educadores e educadoras do campo. CADERNOS CERU, série 2, v. 22, n. 1, junho de 2011. Disponível em:

http://www.revistas.usp.br/ceru/article/view/29475/31334. Acesso em: 07/07/2016.

VEIGA, I. P. A. Projeto Político-Pedagógico e gestão democrática: novos marcos para a educação de qualidade. Revista Retratos da Escola, v. 3, n. 4, p. 163-171, jan./jun. 2009. Disponível em: http://retratosdaescola.emnuvens.com.br/rde/article/viewFile/109/298. Acesso em: 02/03/2017. 
VERGUTZ, C. L. B. O caminho da aprendizagem na pedagogia da alternância e o sujeito alternante. ANPED SUL, SEMINÁRIO DE PESQUISA EM EDUCAÇÃO DA REGIÃO SUL, 9, 2012, São Paulo. Anais... São Paulo: Universidade Federal de São Carlos, 2012. p. 118. Disponível em: http://www.ucs.br/etc/conferencias/index.php/anpedsul/9anpedsul/paper/ viewFile/3216/67. Acesso em: 10/02/2016.

WARTHA, E. J.; SILVA, E. L.; BEJARANO, N. R. R. Cotidiano e Contextualização no Ensino de Química. Química Nova na Escola, Brasil, v. 35, n. 2, p. 84-91, maio 2013. Disponível em: http://qnesc.sbq.org.br/online/qnesc35_2/04-CCD151-12.pdf. Acesso em: 13/11/2018.

Recebido em: 26 de fevereiro de 2019 Aprovado em: 30 de agosto de 2019 